\title{
LAS CUESTIONES DE DEBATE DE LA CIENCIA POLÍTICA COMO DOCENCIA PRÁCTICA EN UN ENTORNO DE ENSEÑANZA SEMIPRESENCIAL Y VIRTUAL
}

The issues of debate of Political Science as a practical teaching in a semi-presential and virtual teaching environment

Recibido: 17 de febrero de 2021

Aceptado: 25 de junio de 2021

Francisco Collado Campaña

Profesor Sustituto Interino

fcolcam@uma.es

Universidad de Málaga

Ángel Valencia Sáiz

Catedrático de Universidad

avalencia@uma.es

Universidad de Málaga

\section{RESUMEN}

Esta investigación en el ámbito docente presenta una propuesta de formación practica para las asignaturas de introducción a la Ciencia Política que tiene como objetivos desarrollar la tolerancia, la argumentación, el juicio crítico, la capacidad de acuerdo, la presentación en público y el interés por la política como competencias entre los alumnos en escenarios de docencia no presenciales. Esta propuesta práctica se centra en la formación de grupos de trabajo dedicados a documentarse, analizar y exponer un posicionamiento político ante una cuestión de debate que esté presente la vida pública y que esté relacionada con el temario de las clases teóricas. Para ello, determinamos las posibles dificultades que pueden encontrarse en escenarios de semipresencialidad y virtualidad, exponemos el diseño y la ejecución de esta propuesta en tres clases y mostramos los resultados tras una encuesta aplicada a los alumnos para conocer el exito de una primera implementación durante el curso 2020/2021. Finalmente, comprobamos como esta propuesta docente permite mejorar competencias básicas y necesarias para el desempeño profesional en el seno de democracias representativas y reforzar los conocimientos teóricos de los estudiantes.

\section{PALABRAS CLAVE}

Ciencia Política, enseñanza virtual, enseñanza semipresencial, argumentación, juicio crítico, tolerancia, capacidad de acuerdo. 


\section{ABSTRACT}

This research in the field of education presents a proposal of practical training for the subjects of introduction to Political Science that aims to develop tolerance, argumentation, critical judgment, capacity of agreement, the public presentation and interest in politics as competencies among students in nonpersonal teaching scenarios. This practical proposal focuses on the formation of working groups dedicated to documenting, analyzing and exposing a political position before a question of debate that is present in public life and that is related to the agenda of theoretical classes. To this end, we determine the possible difficulties that can be encountered in semiattendance or virtual scenarios, expose the design and execution of this proposal in three classes and show the results after a survey applied to the students to know the success of a first implementation during the 2020/2021 academic year. Finally, we can see how this teaching proposal allows us to improve basic and necessary competences for professional performance within representative democracies and to strengthen the theoretical knowledge of students.

\section{KEYWORDS}

Political Science, virtual learning, semi-presential learning, argumentation, criticism, tolerance, capacity of agreement 
Sumario: 1. Introducción a esta propuesta de innovación práctica. 1.1. Estructuración del artículo. 1.2. La Ciencia Política como saber autónomo en la vida pública democrática. 1.3. El mínimo común denominador de las definiciones de política. 1.4. La argumentación y el debate como competencias prácticas en la Ciencia Política. 2. Los handicaps de esta propuesta docente en un escenario a medio camino entre la semipresencialidad y la virtualidad. 3. El diseño de una propuesta de prácticas integradora del debate en Ciencia Política en el contexto de la pandemia del covid-19. 3.1. Cronograma de la primera aplicación de esta propuesta de prácticas. 3.2. Selección del tema de debate. 3.3. Documentación y lectura sobre una cuestión de debate político. 3.4. Organización de la postura grupal ante una cuestión de debate político. 3.5. Exposición de la postura grupal ante la clase. 4. Encuesta aplicada a los alumnos tras la ejecución de esta práctica de debate político. 4.1. Grado de adaptación de la práctica al contexto semipresencial y virtual. 4.2. Grado de desarrollo de conocimientos y efectos sobre el propio juicio. 4.3. Desarrollo de las competencias personales tras la práctica. 4.4. Valoraciones y recomendaciones cualitativas de los alumnos. 5. Conclusiones. 6. Bibliografía.

\section{Introducción a esta propuesta de innovación práctica.}

\subsection{Estructuración del artículo.}

Este artículo recoge una propuesta de prácticas en la enseñanza en Ciencia Política en un contexto de semipresencialidad y virtualidad docentes debido a las restricciones producidas por la crisis sanitaria del coronavirus (covid-19) y sus resultados tras una primera implementación en el Grado en Derecho y Grado en Gestión y Administración Pública (GAP) durante el curso 2020/2021 en la Universidad de Málaga. Desde la pretensión de que la enseñanza teórica de los alumnos en esta materia fuese confrontada con su iniciación ante preguntas o dilemas habituales en esta asignatura, los docentes diseñamos originariamente un sistema de prácticas que pudiese ser desarrollado tanto en el caso de sesiones presenciales como virtuales y siendo conscientes de las posibles restricciones que podíamos encontrarnos en las clases según la evolución de la pandemia durante el curso.

La propuesta docente manifestada se estructura en los siguientes apartados: una introducción que explica los objetivos y los planteamientos de esta propuesta de prácticas, un segundo que manifiesta las diversas dificultades que tanto profesores como alumnos pueden encontrar ante las restricciones en las clases en el contexto de la crisis sanitaria, un tercero con el diseño de las prácticas teniendo en cuenta los anteriores planteamientos y su ejecución en una primera edición, un cuarto que incluye los resultados obtenidos a partir de una encuesta realizada a los estudiantes tras la implementación y unas conclusiones con reflexiones finales sobre esta propuesta docente y su aplicación.

\subsection{La Ciencia Política como saber autónomo en la vida pública democrática.}

Las asignaturas introductorias en Ciencia Política representan una parte fundamental en distintas titulaciones de las Ciencias Jurídicas y Sociales. Los fundamentos en politología en estos itinerarios curriculares mantienen la función de insertar al alumnado en las estructuras, las dinámicas, los actores y los resultados de la política. En ese sentido, la división de la política como objeto de estudio en tres dimensiones ${ }^{1}$ está asociada al conocimiento de los poderes públicos como estructura política (polity), el

\footnotetext{
${ }^{1}$ VALLÈS, J. M. (2006), Ciencia Política: una introducción. Barcelona: Ariel.
} 
comportamiento o proceso político (politics) y las políticas públicas o consecuencias de la acción pública (policy), según una clasificación habitual en la disciplina.

La Ciencia Política como materia de estudio tiene la función de hacer comprensible la realidad política como un área del saber autónoma del ámbito jurídico, gerencial, sociológico o filosófico. Lo que no es óbice para renunciar a su carácter interdisciplinar y para su reconocimiento como una de las disciplinas básicas de las Ciencias Sociales. El proceso de delimitación de un ámbito académico propio de la Ciencia Política se debe situar en la teorización del Estado moderno en obras como El Príncipe de Maquiavelo y El Leviatán de Hobbes durante el Renacimiento. Los inicios de este saber en España se pueden rastrear a partir de la creación del Instituto de Estudios Políticos y la Facultad de Ciencias Políticas de la Universidad Complutense de Madrid en la década de los cuarenta del siglo pasado. Las restricciones intelectuales del franquismo dificultaron un desarrollo autónomo y libre de la Ciencia Política debido a que estaba considerada como un conocimiento potencialmente subversivo para el régimen ${ }^{2}$. De este modo, se establecen cuatro fases de evolución de la disciplina en España desde el final de la Guerra Civil hasta la década de los ochenta del siglo XX. A partir de la década de los noventa, la Ciencia Política en España comienza su etapa de auge e internacionalización en el ámbito académico $^{3}$. Por tanto, la Ciencia Política es un saber que se desarrolló en España de forma gradual conforme se separó del Derecho Público y la Sociología y diversificó sus enfoques dentro de la atmósfera del librepensamiento característico de una democracia representativa.

Siguiendo esta argumentación, los docentes en esta asignatura deben ser capaces de trasladar los debates presentes en la vida pública que no se rigen por argumentaciones exclusivamentes jurídicas y que mantienen una conexión con dilemas clásicos en la disciplina. De este modo, los profesores deben favorecer el desarrollo de las competencias que permitan, dentro del respeto a la libertad intelectual, que los alumnos sean capaces de expresar y justificar de forma lógica y razonable una postura definida en torno a estas cuestiones a partir de su conocimiento teórico mediante metodologías activas ${ }^{4}$. Todo ello sin olvidar que una amplia cantidad de los debates en la vida pública son el resultado de la diversidad de valores y preferencias existentes entre los colectivos de una sociedad democrática y que son gestionados mediante el acuerdo y/o la confrontación.

\subsection{El mínimo común denominador de las definiciones de política.}

La Ciencia Política como asignatura y grado académico está vinculada a su autonomía frente a otras áreas del saber y su institucionalización como parte de las Ciencias Sociales en un sistema democrático que respete la libertad y la pluralidad políticas entre las personas. Si prestamos atención a las definiciones dadas para el concepto de "política" en los manuales de introducción empleados en España podemos encontrar una relación con estos postulados y determinar cuáles son los componentes comunes de este término. La

\footnotetext{
2 JEREZ MIR, M. Y LUQUE, J. (2016), “Treinta años de Ciencia Política en España: profesionalización, expansión y ajuste”, Revista Española de Ciencia Política, núm. 40, pp. 179-215, pp. 180-181 [en línea] https://recyt.fecyt.es/index.php/recp/article/view/41238.

${ }^{3}$ ORTEGA RUIZ, M., REAL-DATO, J. y JEREZ MIR, M. (2021). "Late but not least? Spanish political science's struggle for the internationalisation in the twenty-first century", European Political Science.

${ }^{4}$ GARCÍA, T., ARIAS-GUNDÍN, O., RODRÍGUEZ, C., FIDALGO, R. y ROBLEDO, P. (2017),

"Metodologías activas y desarrollo de competencias en estudiantes universitarios con diferentes estilos de pensamiento", Revista d'Innovació Docent Universitària, núm. 9, pp. 66-80, pp. 78 [en línea] https://revistes.ub.edu/index.php/RIDU/article/download/17124/20179.
} 
obra coordinada por Rafael del Águila establece una división entre las concepciones de la política como la capacidad del ser humano para lograr acuerdos comunes en la sociedad y la política como una actividad conflictiva entre personas y facciones con intereses contrapuestos que intentan imponerse frente a otros ${ }^{5}$. El manual de Josep Maria Vallès reconoce como política, con una visión abierta y holística, a cualquier actividad colectiva mediante la que los miembros de una comunidad gestionan los conflictos derivados de la vida en grupos humanos y cuyo resultado son decisiones vinculantes que benefician a unos y perjudican a otros ${ }^{6}$. Una definición ligeramente distinta la define como el proceso por el cual las comunidades logran objetivos colectivos delimitados por reglas, procedimientos e instituciones y alcanzan decisiones obligatorias que emanan de la autoridad estatal ${ }^{7}$. Sin embargo, esta definición excluiría aquellos elementos que son ajenos al ámbito gubernamental, pero que también implican confrontraciones de intereses y valores. La última aportación sostiene que la política mantiene una controversia gnoseológica entre restringirse a la teoría, la acción y los procesos de gobierno o adoptar una perspectiva holística que abarca todos los ámbitos de la vida en sociedad ${ }^{8}$. Esta afirmación subraya la compleja delimitación de las fronteras de la Ciencia Política frente a otros saberes y las estrategias intelectuales tendentes a la despolitización de determinadas cuestiones mediante su supresión como temas de interés de la disciplina.

Estas definiciones mantienen una tríada de elementos compartidos entre ellas como son los grupos humanos, el conflicto y la vinculación de las decisiones adoptadas. A continuación, explicamos cada uno de estos elementos dentro de la definición de política. Primero, la política es una actividad ejecutada en plural debido a la diversidad de visiones, valores e intereses que pueden coincidir o pugnar entre ellos, pero nunca es una actividad ejercida por un sujeto en singular. En segundo lugar, la vida en sociedad implica la gestión de la pluralidad y las controversias que resulten de ella, lo que se resuelve mediante la deliberación de los representantes en sociedades democráticas frente a la imposición habitual en los contextos institucionales autoritarios. Tercero, el cumplimiento de las decisiones emanadas de las instituciones y el recurso a la coacción en caso de incumplimiento requiere que esas soluciones sean acordes a los valores imperantes en la comunidad. Dicho de otra forma, la adopción de decisiones mediante deliberación y su evaluación por parte de los representantes y la ciudadanía son las reglas de juego básicas de la democracia. Por ello, el debate y la argumentación como medio de gestión de los conflictos que se derivan de una sociedad plural y libre también deben ser habilidades y valores desarrollados en el aprendizaje de la Ciencia Política.

\subsection{La argumentación y el debate como competencias prácticas en la Ciencia Política.}

Los métodos que de forma más lógica permiten establecer las reglas de juego y que son acordes a los valores de las democracias representativas son el debate y la argumentación. De esta forma, representan cualidades que los profesores de Ciencia Política deben integrar y promover entre sus alumnos en la formación práctica de la asignatura. Como ha señalado recientemente Josep Maria Vallès, los análisis rigurosos y críticos de los politólogos representan su principal aportación de servicio útil a la propia sociedad $^{9}$. A partir de esta perspectiva, proponemos que las sesiones prácticas de la

\footnotetext{
5 ÁGUILA, R. (1997), pp. 21-22.

${ }^{6}$ VALLÈS, J. M. (2006), Ciencia Política: una introducción. Barcelona: Ariel, pp. 18-20.

${ }^{7}$ SODARO, M. (2006), Política y Ciencia Política: una introducción. Madrid: McGraw Hill, pp. 1-2.

${ }^{8}$ CAMINAL, M. (2011), Manual de Ciencia Política. Madrid: Tecnos, p. 32.

${ }^{9}$ VALLÈS, J. M. (2020), ¿Para qué servimos los politólogos? Madrid: La Catarata.
} 
asignaturas de Introducción o Fundamentos de la Ciencia Política deben ir dirigidas a que los estudiantes se enfrenten a preguntas vigentes en esta materia y que a su vez son debates habituales en la vida pública a partir del estudio guiado dentro de los métodos de enseñanza activa ${ }^{10}$. Por tanto, la docencia en Ciencia Política no debe centrarse exclusivamente en la medición de la calidad, sino que debe insertar un componente de reflexividad que incluya elementos de carácter ético y juicio crítico entre el alumnado ${ }^{11}$. Además, los cambios continuos a los que está sometido el mundo académico requieren que la transmisión convencional de conocimientos del profesor hacia el estudiante sea complementada con la promoción de habilidades que favorezcan la definición o autoidentificación de los estudiantes y su capacidad para intervenir desde esa posición en su entorno ${ }^{12}$. De este modo, la consideración de la argumentación como un acto discursivo encaminado a influir sobre las creencias, los valores y los conocimientos de la audiencia para hacerlos acordes con los del emisor, representa una cualidad que debe fomentarse entre los alumnos de Ciencias Sociales y Jurídicas ${ }^{13}$. Entre los casos que han implementado estas prácticas docentes en la universidad española merece especial mención dos antecedentes. En primer lugar, un proyecto educativo implementado en la Universidad de Salamanca entre los estudiantes de Derecho, Ciencia Política y Criminología que les introducía en el análisis de un problema de la realidad política para el cual se documentaban, estructuraban la información y expresaban finalmente una postura desde su propia opinión crítica ${ }^{14}$. En segundo lugar, es destacable la experiencia del profesor Rodríguez Prieto en el fomento del debate como una fórmula para que el alumno desarrolle su responsabilidad como sujeto activo en su formación ${ }^{15}$. Sin embargo, esta última práctica implica el riesgo de definir una línea de pensamiento que puede ubicar al alumno en una determinada posición teórica o ideológica cercana a la del profesor, negándole su propia autonomía y libertad intelectual.

La propuesta de docencia práctica que exponemos en este artículo introduce la argumentación y el auto-posicionamiento del alumnado como habilidades prácticas desarrolladas a través de cuatro etapas mediante el esquema "razonamiento, discusión y argumentación" dentro de un equipo de trabajo ${ }^{16}$. En primer lugar, los alumnos desarrollan su conocimiento sobre una pregunta clásica en la asignatura y la confrontan (ejemplo: ¿es proporcional el sistema electoral en España?). Segundo, los estudiantes se documentan y seleccionan fuentes que favorezcan su conocimiento referente a las distintas respuestas y/o posturas en torno a dicha cuestión. En tercer lugar, el grupo de alumnos analiza las lecturas para diseñar su propia postura ya sea adhiriéndose a alguna de las existentes o conformando una posición ecléctica. Finalmente, el grupo deberá

\footnotetext{
${ }^{10}$ MERCER, N. (1997). La construcción guiada del conocimiento: el habla de profesores y alumnos. Barcelona: Paidós.

${ }^{11}$ ESTEBAN, J. (2005), Universidades reflexivas: una perspectiva filosófica. Barcelona: Laertes.

12 PRENSKY, M. (2015), El mundo necesita un nuevo currículum. Habilidades para pensar, crear, relacionarse y actuar. Madrid: SM.

${ }^{13}$ CROSS, A. (2003), Convencer en clase: argumentación y discurso docente. Barcelona: Ariel, pp. 1314.

${ }^{14}$ CARRIZO, A. (2016), El debate académico de competición como instrumento para el aprendizaje de cuestiones de Derecho, Ciencia Política y Criminología. Memoria final del proyecto ID 2016/032.

Salamanca: Universidad de Salamanca [en línea]

https://gredos.usal.es/bitstream/handle/10366/135352/MID_16_032.pdf?sequence=1 .

${ }^{15}$ RODRÍGUEZ PRIETO, R. (2012), "El debate como estrategia de innovación docente: experiencias en Filosofía del Derecho y Teoría de la Cultura", Revista UPO Innova, vol. 1, pp. 493-503, pp. 500 [en línea] https://www.upo.es/revistas/index.php/upoinnova/article/view/124.

16 JIMÉNEZ, M. P. (2010), 10 Ideas clave. Competencias en argumentación y uso de pruebas. Barcelona: Graó.
} 
presentar la importancia de la pregunta trabajada, mostrar una panorámica de las distintas respuestas para afrontarla y razonar su postura ante una audiencia formada por el profesor y el resto de la clase. Esta etapa final se corresponde con lo que podemos calificar como el discurso del propio grupo, aunque nosotros lo denominamos posicionamiento en este artículo. Este discurso o posicionamiento implica la agregación de todas las argumentaciones que se han expuesto, siendo el elemento global de las mismas y el producto final de este proceso práctico ${ }^{17}$. En esta última parte, es recomendable habilitar un turno de preguntas o réplicas por parte del público para evaluar la fundamentación de los argumentos del grupo.

\section{Los handicaps de esta propuesta docente en un escenario a medio camino entre} la semipresencialidad y la virtualidad.

La propuesta docente inicial supone que los alumnos desarrollan su capacidad de análisis, razonamiento y argumentación en dos niveles de interacción por parte del grupo de trabajo: entre sus miembros y desde el equipo hacia el resto del aula. En esta línea, se promociona la aplicación de las anteriores habilidades tanto entre el equipo como ante una audiencia. En un principio, esta propuesta de práctica resulta óptima en caso de disfrutar de un entorno presencial, pero siendo conscientes que no disfrutaríamos de estas circunstancias a comienzo del curso 2020/2021 se tomaron medidas para que se pudiese ejecutar tanto en un contexto semipresencial como en uno virtual (el cual variaba en función de las restricciones). A continuación, explicamos las distintas etapas y sus correspondientes riesgos teniendo en cuenta cualquiera de esos dos escenarios:

1) Selección del tema de debate: el estudiante que se inicia, por regla general, desconoce las preguntas y dilemas clásicos de la Ciencia Política así como su vinculación con la actualidad política. Esto requiere que el docente realice una labor de guía para que el alumno opte por alguna de las cuestiones y cuya ejecución conllevaría un tiempo prudencial. A ello se añade que es deseable que cada equipo de trabajo se encargue de temas distintos y no se solapen o repitan entre sí y sea posible mostar una visión global del temario de la asignatura al conjunto de la clase.

2) Documentación y lectura sobre el tema de debate: el desconocimiento inicial del alumno también está presente en esta fase en la que debe seleccionar fuentes y acceder a las bibliotecas universitarias. Esto último supone que no todos los alumnos ni siempre van a tener acceso a manuales, monografías y textos necesarios debido a las restricciones de acceso en las salas. Asimismo, puede que los alumnos eviten tener una visión plural de autores, enfoques y teorías que aporten una respuesta a la cuestión planteada, suponiendo un sesgo considerable.

3) Organización de la postura grupal: conforme los alumnos disponen de un tema de debate y han realizado las lecturas correspondientes, ya están en disposición de analizar la información y acordar un posicionamiento colectivo. Esto puede quedar impedido por las dificultades del grupo para reunirse físicamente. Pese a ello, esta es la fase de menor riesgo ya que el trabajo en equipo puede ser coordinado y puesto en común por parte de los alumnos mediante reuniones virtuales.

4) Exposición del posicionamiento grupal: la exposición puede que no se produzca con la totalidad de la clase en la sesión y que el tiempo de las réplicas de los alumnos y

\footnotetext{
${ }^{17}$ MARAFIOTI, R. (2003). Los patrones de la argumentación: la argumentación en los clásicos y en el siglo XX. Buenos Aires: Biblos, pp. 39-40.
} 
del profesor se vea limitado. También cabe la posibilidad de que no todos los alumnos disfruten de una visión completa de los temas que han abordado cada uno de los grupos.

Ante estas limitaciones, era preciso que el diseño de estas prácticas en Ciencia Política permitiesen salvar y/o evitar los riesgos expresado y garantizase una realización óptima dentro de estas circunstancias.

3. El diseño de una propuesta de prácticas integradora del debate en Ciencia Política en el contexto de la pandemia del covid-19.

Nuestra propuesta de prácticas introduce la argumentación, el aprendizaje y el debate en torno a cuestiones tanto clásicas como vigentes en las asignaturas de introducción y/o iniciación a la Ciencia Política. A continuación, se expone el diseño de las tareas, las habilidades y los objetivos de este proyecto docente desglosado para cada una de la etapas que hemos establecido, como mostramos en la tabla 1. A grandes rasgos, las metas de este diseño docente son: promover la iniciación del estudiante en debates académicos que tiene una conexión con la vida pública, favorecer la habilidad del alumnado para informarse sobre estos temas y fomentar su capacidad para acordar, estructurar y expresar una postura colectiva de forma lógica.

Los profesores hemos trasladado las instrucciones necesarias para realizar esta práctica de debate mediante dos sesiones de clase y un documento explicativo que hemos puesto a su disposición en el aula virtual de la asignatura.

\begin{tabular}{|c|c|c|}
\hline Etapas y tareas & Habilidades & Objetivos \\
\hline $\begin{array}{l}\text { Selección del tema } \\
\text { de debate }\end{array}$ & $\begin{array}{l}\text { Conocimiento de la variedad } \\
\text { de autores y de enfoques } \\
\text { sobre un tema de Ciencia } \\
\text { Política }\end{array}$ & $\begin{array}{l}\text { Documentarse sobre un tema de } \\
\text { debate en Ciencia Política }\end{array}$ \\
\hline \multirow[t]{3}{*}{$\begin{array}{l}\text { Documentación y } \\
\text { lectura sobre un } \\
\text { tema de debate } \\
\text { político }\end{array}$} & \begin{tabular}{llr}
\multicolumn{2}{l}{ Conocimiento de } & las \\
diversas fuentes & de \\
información en & Ciencia \\
Política & & \\
\end{tabular} & $\begin{array}{l}\text { Distinguir y estructurar las } \\
\text { distintas respuestas ante un } \\
\text { tema de debate de Ciencia } \\
\text { Política }\end{array}$ \\
\hline & $\begin{array}{l}\text { Conocimiento de la variedad } \\
\text { de autores y corrientes de } \\
\text { enfoques sobre un tema de } \\
\text { debate en Ciencia Política }\end{array}$ & $\begin{array}{l}\text { Desarrollar la tolerancia ante } \\
\text { distintos enfoques y corrientes } \\
\text { de pensamiento político }\end{array}$ \\
\hline & $\begin{array}{l}\text { Conocimiento sobre los } \\
\text { argumentos y contenidos de } \\
\text { distintos autores y enfoques } \\
\text { sobre un tema de debate de } \\
\text { Ciencia Política }\end{array}$ & $\begin{array}{l}\text { Conocer los argumentos, } \\
\text { ventajas y críticas de las } \\
\text { posturas de distintos autores y } \\
\text { enfoques sobre un tema de } \\
\text { debate de Ciencia Política }\end{array}$ \\
\hline \multirow[t]{2}{*}{$\begin{array}{l}\text { Organización de la } \\
\text { postura grupal ante } \\
\text { un debate político }\end{array}$} & $\begin{array}{l}\text { Acuerdo y/o negociación en } \\
\text { la estructuración de una } \\
\text { respuesta grupal }\end{array}$ & $\begin{array}{l}\text { Desarrollar la capacidad de } \\
\text { acuerdo y/o consenso ante un } \\
\text { tema de debate político de forma } \\
\text { colectiva }\end{array}$ \\
\hline & $\begin{array}{l}\text { Estructuración de los } \\
\text { argumentos de la postura } \\
\text { grupal }\end{array}$ & $\begin{array}{l}\text { Favorecer la capacidad de } \\
\text { estructuración de la } \\
\text { argumentación de una postura } \\
\text { colectiva ante un tema de debate } \\
\text { político }\end{array}$ \\
\hline
\end{tabular}




\begin{tabular}{|ll|l|l|}
\hline $\begin{array}{l}\text { Exposición de la } \\
\text { posición grupal } \\
\text { ante un } \\
\text { político }\end{array}$ & $\begin{array}{l}\text { Comunicación de un tema de } \\
\text { debate político y su } \\
\text { importancia }\end{array}$ & $\begin{array}{l}\text { Desarrollar la capacidad de } \\
\text { comprensión y comunicación de } \\
\text { la relevancia de un tema de } \\
\text { debate político ante una } \\
\text { audiencia }\end{array}$ \\
\cline { 2 - 4 } & $\begin{array}{l}\text { Comunicación de las distintas } \\
\text { respuestas y/o posturas ante } \\
\text { un tema de debate político }\end{array}$ & $\begin{array}{l}\text { Desarrollar la tolerancia y la } \\
\text { capacidad de comunicación de } \\
\text { las distintas posturas en torno a } \\
\text { un tema de debate político ante } \\
\text { una audiencia }\end{array}$ \\
& $\begin{array}{l}\text { Argumentación de la postura } \\
\text { grupal ante un tema de } \\
\text { debate político }\end{array}$ & $\begin{array}{l}\text { Favorecer la capacidad de } \\
\text { argumentación y defensa lógica } \\
\text { de la postura colectiva adoptada } \\
\text { ante un tema de debate político } \\
\text { ante una audiencia }\end{array}$ \\
\hline & $\begin{array}{l}\text { Defensa de la postura grupal } \\
\text { ante las críticas o réplicas en } \\
\text { torno a un tema de debate } \\
\text { político }\end{array}$ & $\begin{array}{l}\text { Desarrollar la capacidad de } \\
\text { respuesta lógica a las críticas a } \\
\text { los argumentos expuestos ante } \\
\text { una audiencia }\end{array}$ \\
\hline
\end{tabular}

Tabla 1. Etapas y tareas, habilidades y objetivos de la propuesta docente de prácticas en Ciencia Política. Elaboración propia.

\subsection{Cronograma de la primera aplicación de esta propuesta de prácticas.}

La aplicación de este diseño que hemos realizado se inició en octubre de 2020 y ha abarcado hasta enero de 2021 como se observa en la tabla 2. La primera etapa de selección de los temas de debate que hemos coordinado los docentes se ejecutó al comienzo del curso durante el mes de octubre. La segunda etapa de documentación por parte de los estudiantes y la tercera referente a la organización de los posicionamientos de los grupos se sitúan entre octubre y comienzos de diciembre. Debemos destacar que a principios de noviembre, la Universidad de Málaga pasó de un escenario de docencia semipresencial a uno virtual debido a las restricciones autonómicas decretadas a causa del covid-19 y se ha mantenido así hasta el final del primer semestre en febrero del siguiente año. Finalmente, las exposiciones de los equipos de alumnos han tenido lugar entre el mes de diciembre y enero.

\begin{tabular}{|l|l|l|}
\hline Etapas & Duración & Entorno de docencia \\
\hline Selección del tema de debate & Octubre de 2020 & Semipresencial \\
\hline $\begin{array}{l}\text { Documentación y lectura sobre } \\
\text { un tema de debate político }\end{array}$ & $\begin{array}{l}\text { Desde octubre a } \\
\text { diciembre de 2020 }\end{array}$ & Semipresencial y virtual \\
\hline $\begin{array}{l}\text { Organización de la postura } \\
\text { grupal ante un debate político }\end{array}$ & $\begin{array}{l}\text { Desde octubre a } \\
\text { diciembre de 2020 }\end{array}$ & Semipresencial y virtual \\
\hline
\end{tabular}




\begin{tabular}{|l|l|l|}
\hline $\begin{array}{l}\text { Exposición de la posición } \\
\text { grupal ante un debate político }\end{array}$ & $\begin{array}{l}\text { Entre diciembre de 2020 } \\
\text { y enero de 2021 }\end{array}$ & Virtual \\
& & \\
\hline
\end{tabular}

Tabla 2. Cronograma de aplicación de la propuesta docente sobre argumentación y debate de una cuestión clásica en Ciencia Política.

\subsection{Selección del tema de debate}

En la primera etapa hemos trasladado los temas de la teoría de la asignatura a cuestiones de debate respectivamente, es decir, cada tema de teoría funciona como un macrotema o ámbito desde el que los docentes hemos escogido uno más concreto y teniendo en cuenta su vinculación con la actualidad política, como ilustramos en la tabla 3. Originariamente, hablamos de los diez temas de la parte teórica y que vienen dados a partir de una obra de referencia de la asignatura (Águila, 1997). Estos diez temas de teoría o macrotemas son los siguientes: la política y el poder, el Estado moderno, el Estado liberal, el fascismo y socialismo como rupturas del Estado liberal, el Estado del Bienestar, la calidad democrática y los modelos de democracia, la comunicación política, los sistemas electorales, los partidos políticos y la organización territorial del poder. A partir de cada uno de ellos se establecen un tema y una o varias cuestiones de debate.

\begin{tabular}{|c|c|c|}
\hline Tema de teoría & Tema de debate & Cuestiones de debate \\
\hline Política y poder & La visión de la política & $\begin{array}{l}\text { ¿La política es una actividad } \\
\text { positiva o negativa? }\end{array}$ \\
\hline Estado moderno & $\begin{array}{l}\text { Surgimiento de } \\
\text { después de la Edad moderna } \\
\text { y/o problemática de los } \\
\text { Estados fallidos }\end{array}$ & $\begin{array}{l}\text { ¿Es recomendable que un } \\
\text { territorio experimente un } \\
\text { largo proceso histórico para } \\
\text { convertirse con éxito en un } \\
\text { Estado? }\end{array}$ \\
\hline Estado liberal & $\begin{array}{l}\text { Democracia representativa } \\
\text { versus democracia directa }\end{array}$ & $\begin{array}{l}\text { ¿Es preferible una } \\
\text { democracia representativa o } \\
\text { una democracia directa en el } \\
\text { presente? }\end{array}$ \\
\hline $\begin{array}{l}\text { Fascismo y socialismo } \\
\text { como rupturas con el } \\
\text { Estado liberal }\end{array}$ & $\begin{array}{l}\text { El regreso de los fascismos y } \\
\text { los partidos de extrema } \\
\text { derecha }\end{array}$ & $\begin{array}{l}\text { ¿Es posible que se } \\
\text { reproduzcan Estados o } \\
\text { partidos que puedan ser } \\
\text { calificados como "fascistas" } \\
\text { en la actualidad? }\end{array}$ \\
\hline Bienestar & $\begin{array}{l}\text { La crisis del Estado del } \\
\text { Bienestar }\end{array}$ & $\begin{array}{l}\text { ¿Es posible garantizar la } \\
\text { continuidad del Estado del } \\
\text { Bienestar o es preferible un } \\
\text { Estado mínimo que } \\
\text { disminuya } \\
\text { competencias? }\end{array}$ \\
\hline $\begin{array}{l}\text { Calidad democrática y } \\
\text { modelos de } \\
\text { democracia }\end{array}$ & Modelos de democracia & $\begin{array}{l}\text { ¿Cuál es el modelo de } \\
\text { democracia más óptimo y } \\
\text { cómo puede ser llevado a la } \\
\text { práctica? }\end{array}$ \\
\hline Comunicación política & $\begin{array}{l}\text { Las redes sociales como nuevo } \\
\text { foro para la opinión pública }\end{array}$ & $\begin{array}{l}\text { ¿Las redes sociales de } \\
\text { Internet son un instrumento }\end{array}$ \\
\hline
\end{tabular}




\begin{tabular}{|l|l|l|}
\hline & & $\begin{array}{l}\text { positivo para la } \\
\text { participación política o son } \\
\text { un instrumento de control } \\
\text { que limita la deliberación? }\end{array}$ \\
\hline Sistemas electorales & El sistema electoral español & $\begin{array}{l}\text { iEl sistema electoral en } \\
\text { España tiende hacia la } \\
\text { gobernabilidad, hacia la } \\
\text { proporcionalidad pos } \\
\text { mantiene un equilibrio entre } \\
\text { ambos? }\end{array}$ \\
\hline Partidos políticos & $\begin{array}{l}\text { Nuevos partidos políticos en } \\
\text { España }\end{array}$ & $\begin{array}{l}\text { iCuáles son los factores que } \\
\text { han propiciado el } \\
\text { surgimiento y crecimiento } \\
\text { de nuevos partidos políticos } \\
\text { en España? }\end{array}$ \\
\hline $\begin{array}{l}\text { Organización } \\
\text { territorial del poder }\end{array}$ & La Unión Europea & $\begin{array}{l}\text { iEs preferible que la } \\
\text { integración europea avance } \\
\text { hacia una federación de } \\
\text { Estados o es preferible } \\
\text { garantizar la independencia } \\
\text { de los Estados miembros? }\end{array}$ \\
\hline
\end{tabular}

Tabla 3. Temas de teoría, temas de debate y cuestiones de debate. Elaboración propia.

Desde el establecimiento de esta estructura temática, los docentes hemos solicitado a los alumnos que formen grupos (hemos optado por un tamaño entre 3 y 5 integrantes) en función del tamaño de la clase ${ }^{18}$ y su notificación. Teniendo en cuenta este criterio, hemos buscado que la cantidad de equipos de trabajo en cada clase fuese igual o inferior a los diez temas propuestos. Una vez hemos dispuesto de la lista de grupos de alumnos hemos distribuido los diez temas o número de temas correspondientes entre los grupos de cada clase $^{19}$.

Esta distribución de temas entre los equipos de estudiantes se ha realizado presencialmente durante la segunda sesión de prácticas de la asignatura en cada clase y teniendo en cuenta que esa ordenación debía ser operativa tanto en un escenario de semipresencialidad como de virtualidad. El reparto lo hemos realizado por sorteo mediante la asignación de un número a cada equipo de alumnos según una tirada de dado, después estos grupos los hemos ordenado del número menor al mayor y consecutivamente hemos asignado las cuestiones de debate según el número del tema en el temario con el cual se correspondían. El resultado de este reparto ha sido óptimo: once, siete, ocho y diez equipos en cuatro subgrupos de la asignatura de Ciencia Política del Grado en Derecho y diez equipos en los dos subgrupos de clases prácticas de Introducción a la Ciencia Política del Grado en GAP. Sólo el primer subgrupo que hemos mencionado anteriormente registró la duplicidad de un tema debido a la cantidad de alumnos.

En síntesis, cada equipo de alumnos ha trabajado una pregunta o cuestión referida a uno de los temas de debate que se desprenden de un tema teórico. Subrayamos la

\footnotetext{
${ }^{18}$ Las clases prácticas de la Universidad de Málaga se descomponen en grupos más pequeños (llamados "subgrupos" o "grupos reducidos") a los alumnos de una clase para su impartición.

${ }^{19} \mathrm{Si}$ son diez grupos se reparten los diez temas, si son nueve grupos se suprime un tema al azar y se reparten nueve temas, etc.
} 
importancia de buscar un equilibrio entre la cantidad de temas de teoría y la cantidad de grupos de trabajo en función del tamaño de cada clase.

\subsection{Documentación y lectura sobre una cuestión de debate político.}

La fase de selección de fuentes de información y lectura representa el segundo hito de este proceso. A raíz de las cuestiones de debate, hemos elaborado una selección de referencias bibliográficas básicas (artículos, capítulos de libro, informes, etc.) que permiten responder a cada una de ellas. Estas lecturas no han tenido un carácter obligatorio, y por tanto, hemos manifestado a los alumnos que tenían libertad para documentarse siempre que ofreciesen una visión panorámica y lo cual es deseable para su formación. Dicho de otra forma, esta selección de fuentes tenía la intención de servir de punto de partida para los alumnos que no estuviesen versados con el tema y la cuestión de debate, pero no era imprescindible para su buen desempeño. Los criterios que hemos tenido en cuenta para elegir estas lecturas son los siguientes:

1) Los textos debían ser accesibles a través de Internet para permitir que el estudiante pueda trabajar desde su casa y/o no esté limitado por el acesso presencial a las bibliotecas universitarias. Esta decisión docente ha permitido salvar las dificultades planteadas en la segunda fase, especialmente por las restricciones de acceso y los casos de estudiantes que puedan ser especialmente vulnerables ante el covid-19.

2) Hemos intentado garantizar una visión plural en torno a las teorías, autores y posturas en cada una de las cuestiones de debate, evitando posibles sesgos derivados de la selección que pudieran realizar los alumnos de forma aislada.

3) Cada uno de los temas de debate recoge entre tres y cuatro referencias bibliográficas para cada cuestión de debate de modo que pueda ser una labor abarcable por parte del equipo de alumnos y puedan distribuir su análisis.

A partir de aquí, hemos dispuesto un listado de 34 lecturas repartidas entre los diez temas y cuestiones de debate de esta propuesta de prácticas ${ }^{20}$. De esta forma, el grupo de alumnos puede disfrutar de una visión panorámica de cada uno de los debates planteados y tiene la posibilidad tanto de posicionarse en alguna de las posturas tradicionales en torno al mismo o definir una propia.

\subsection{Organización de la postura grupal ante una cuestión de debate político.}

El siguiente paso consiste en que los alumnos se decantan por una postura ante la cuestión de debate planteada y van diseñando su exposición. Desde aquí, hemos exigido a los estudiantes que estructurasen su puesta en escena en tres partes: una primera consistente en presentar y explicar la importancia de la cuestión que han trabajado, una tercerca en la que muestran las posturas tradicionales de la Ciencia Política en torno a esa pregunta y finalmente una argumentación de la postura que ellos han elegido.

Tanto esta fase como la anterior suponen la lectura y la organización de la exposición que pueden ser realizadas por los estudiantes en sus hogares a través de reuniones telemáticas con sus compañeros. Al respecto, hemos promovido el uso de aplicaciones como Microsoft Teams y Google Meet para favorecer el desarrollo de estas tareas y hemos organizado tutorías virtuales en aquellos casos de grupos que han planteado consultas o necesitaban resolver dudas. Así, hemos evitado que los

\footnotetext{
${ }^{20}$ Este listado de referencias bibliográficas no se incluye debido a la falta de espacio, pero estamos abiertos a ponerlos en disposición de aquellos docentes que nos las soliciten.
} 
alumnos requieran de un contacto presencial para trabajar tanto entre ellos como para la asistencia docente.

\subsection{Exposición de la postura grupal ante la clase.}

Finalmente, los grupos de estudiantes han realizado la exposición que representa el culmen de su trabajo al final del semestre. Nuestro diseño original contemplaba que las intervenciones se realizarían en un entorno de semipresencialidad con entre uno y dos portavoces ${ }^{21}$ por grupo, siendo esas las instrucciones que se dieron al comienzo del curso. En la práctica real, las intervenciones han tenido lugar virtualmente a través de Google Meet debido al cambio de semipresencialidad a virtualidad establecido en noviembre. Estas exposiciones en la clase virtual las han realizado ante los profesores y el resto de compañeros de la asignatura, con una duración aproximada de 10 minutos para los alumnos de Ciencia Política en el Grado de Derecho y de 15 minutos para los alumnos en el Grado de Gestión y Administración Pública. Esta asignación de tiempo ha dependido de la cantidad de grupos de alumnos por clase y la duración de horario de la sesión ${ }^{22}$. Hemos observado como la duración de 10 minutos es reducida para un desempeño óptimo, mientras que la de un cuarto de hora es más adecuada para este formato de exposición.

De este modo, los estudiantes de cada equipo han presentado su pregunta, han realizado una visión panorámica de las posturas y una argumentación de la posición ante la cuestión de debate. Sólo hemos encontrado tres casos anómalos de grupos que no han operado adecuadamente: uno en el Grado en Derecho debido a una falta de coordinación de los alumnos y dos en el Grado en GAP debido a equipos con un escaso rendimiento ${ }^{23}$ e interés por el trabajo. Después de cada exposición de cada grupo hemos procurado realizar preguntas para evaluar el conocimiento y juicio de los estudiantes, aunque no ha sido posible siempre debido a la escasez de tiempo.

En la evaluación de las exposiciones, hemos tenido como criterios principalmente el conocimiento de los estudiantes sobre la cuestión de debate y su capacidad para posicionarse al respecto. También, hemos valorado el grado de dificultad y el carácter técnico que revisten algunos temas frente a otros, como puede ser el conocimiento en torno al sistema electoral general que reviste una considerable complejidad. Por último, es importante en la medida de lo posible que el profesor no evalúe con una perspectiva adoctrinadora a los alumnos en términos de ideas y valores políticos, favoreciendo la libre expresión dentro de los cauces explicitados anteriormente. De lo contrario, el docente estaría pervirtiendo el espíritu y los objetivos de esta práctica de debate que se enmarcan en valores democráticos básicos.

\section{Encuesta aplicada a los alumnos tras la ejecución de esta práctica de debate político.}

La propuesta de práctica docente ha sido ejecutada entre un total de 228 alumnos que han cursado una asignatura introductoria a la politología: 75 y 78 estudiantes de

\footnotetext{
${ }^{21}$ Este era el número máximo de alumnos de cada grupo que permitíamos que expusieran en caso de haber sido en un entorno semipresencial y atendiendo a un criterio de distanciamiento social.

${ }^{22} \mathrm{Al}$ respecto, debemos señalar que la duración de las clases se vio reducida debido al paso de docencia semipresencial a virtual debido a las restricciones decretadas por el Gobierno de la Junta de Andalucía en noviembre de 2020 a raíz del agravamiento de la pandemia.

${ }^{23}$ En uno de estos grupos los alumnos no se preocuparon por seguir las instrucciones del profesor dadas en clase y en el documento explicativo de esta práctica.
} 
dos clases de Ciencia Política en el Grado de Derecho y 75 estudiantes de Introducción a la Ciencia Política del Grado en Gestión y Administración pública.

Al final del semestre, una vez han finalizado las exposiciones en estas asignaturas hemos elaborado y aplicado una encuesta entre los estudiantes que han participado en este trabajo y que se ha presentado a través del Campus Virtual de la Universidad. Los objetivos de esta encuesta se pueden sintetizar principalmente en: conocer: el grado de adaptación de esta práctica en un contexto de docencia semipresencial y virtual, si la práctica había producido algún cambio cognitivo y de juicio entre los alumnos, el efecto de esta práctica en el desarrollo de las competencias personales y la recepción de valoraciones y recomendaciones por parte de los estudiantes. Este estudio ha constado de 10 preguntas de respuesta obligatoria y ha sido aplicado entre el 11 de enero y el 15 de febrero de 2020. Esta consulta ha recibido un grado de respuesta que representa el 47,36\% del alumnado que ha participado en esta dinámica docente (el 50,8\% en el caso de las dos clases del Grado en Derecho y el 26,6\% del Grado de Gestión y Administración Pública).

\subsection{Grado de adaptación de la práctica al contexto semipresencial y virtual.}

Las tres primeras preguntas de nuestra encuesta han ido destinadas a conocer en qué medida los alumnos se sienten satisfechos con las adaptaciones realizadas de esta práctica al contexto del covid-19. La primera cuestión planteada muestra como más del $90 \%$ de los estudiantes consultados en las tres clases han calificado que la propuesta estaba adecuada a las restricciones de la docencia semipresencial (gráfico 1). Al respecto, debemos destacar que más del $60 \%$ califica como "bastante" el grado de adaptación a partir de las medidas tomadas por el profesorado. Tan sólo una minoría inferior al $10 \%$ entre la clase A del Grado en Derecho señala que estaba "poco" adecuada al contexto.

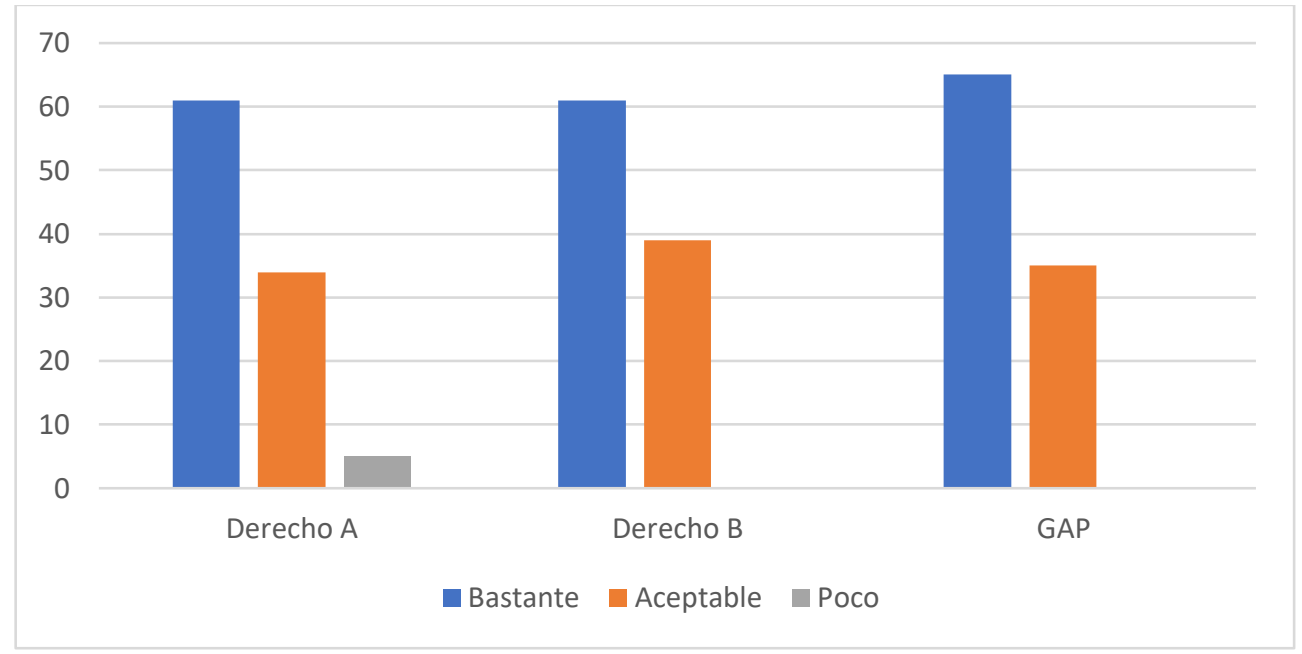

Gráfico 1. Valora el grado de adaptación del trabajo de exposición en grupo que ha realizado en esta asignatura a las clases semipresenciales. Elaboración propia.

Siguiendo con estas cuestiones, la segunda pregunta se sitúa dentro del tránsito de docencia semipresencial a virtual que experimentamos en noviembre de 2020, lo que requirió un traslado prácticamente desde las aulas al entorno cibernético (gráfico 2). En ese sentido, nos interesaba conocer en qué medida los alumnos consideraron que 
ese cambio pudo afectar al funcionamiento de esta práctica. Si agregamos las categorías "mucho" y "algo", podemos afirmar que más del 55\% de los alumnos encuestados en cada clase percibió una disrupción considerable. En cambio, sólo una minoría del $11 \%$ o menos no sufrió un gran cambio. Esto evidentemente implica que deben estudiarse correctivos que permitan controlar estas coyunturas en la medida de lo posible por parte de los docentes.

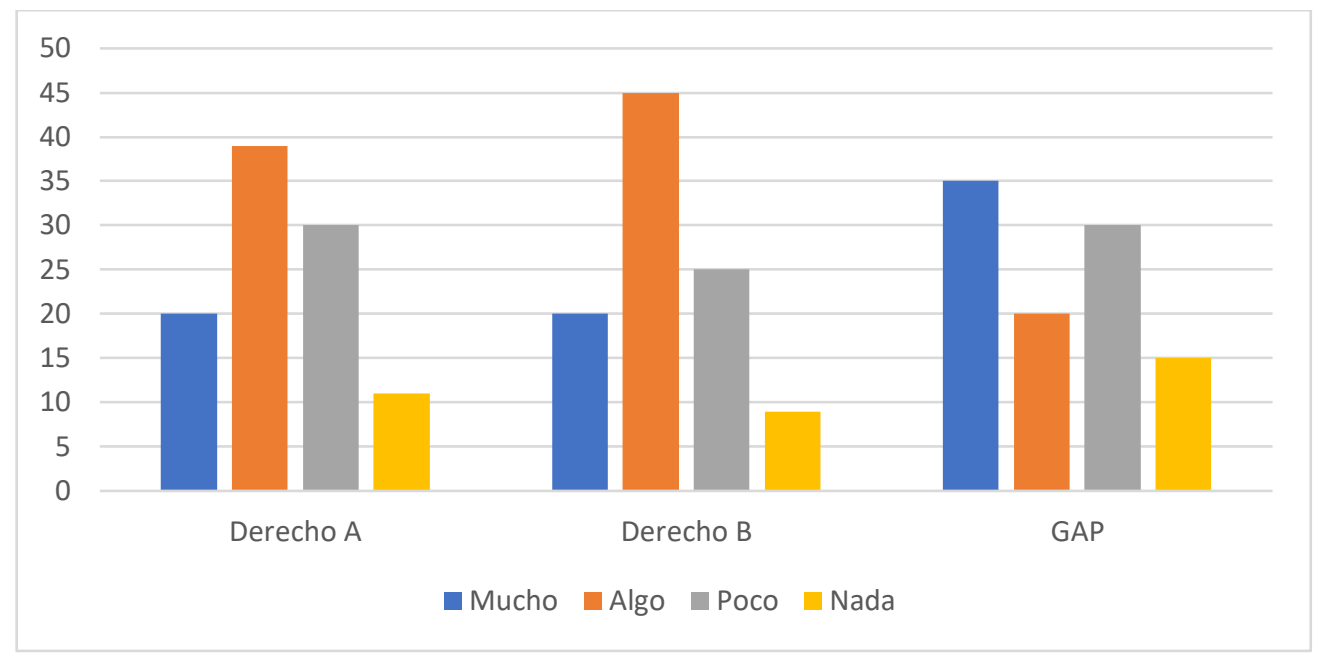

Gráfico 2. ¿Experimentaste un gran cambio en la realización de este trabajo desde las clases semiprepresenciales a las clases virtuales durante el mes de noviembre? Elaboración propia.

La tercera cuestión pretende conocer qué percepción han tenido los estudiantes sobre la adaptación de las distintas etapas de la práctica en el contexto semipresencial y virtual con una valoración entre 1 y 5 en una escala Likert (gráfico 3). En primer lugar, todas las etapas registran una valoración media de cumpimiento que se sitúa entre el 4,1 y el 4,3. Una laguna o calificación baja que merece especial mención se encuentra en la clase del Grado en GAP que califica con un 3,9 la variedad de autores que se le ha ofrecido. Por lo que, es indicativo que puede ser necesaria una revisión de la selección de lecturas que hemos planteado a los alumnos y/o buscar otro método que anime a una búsqueda activa de información por su parte. 


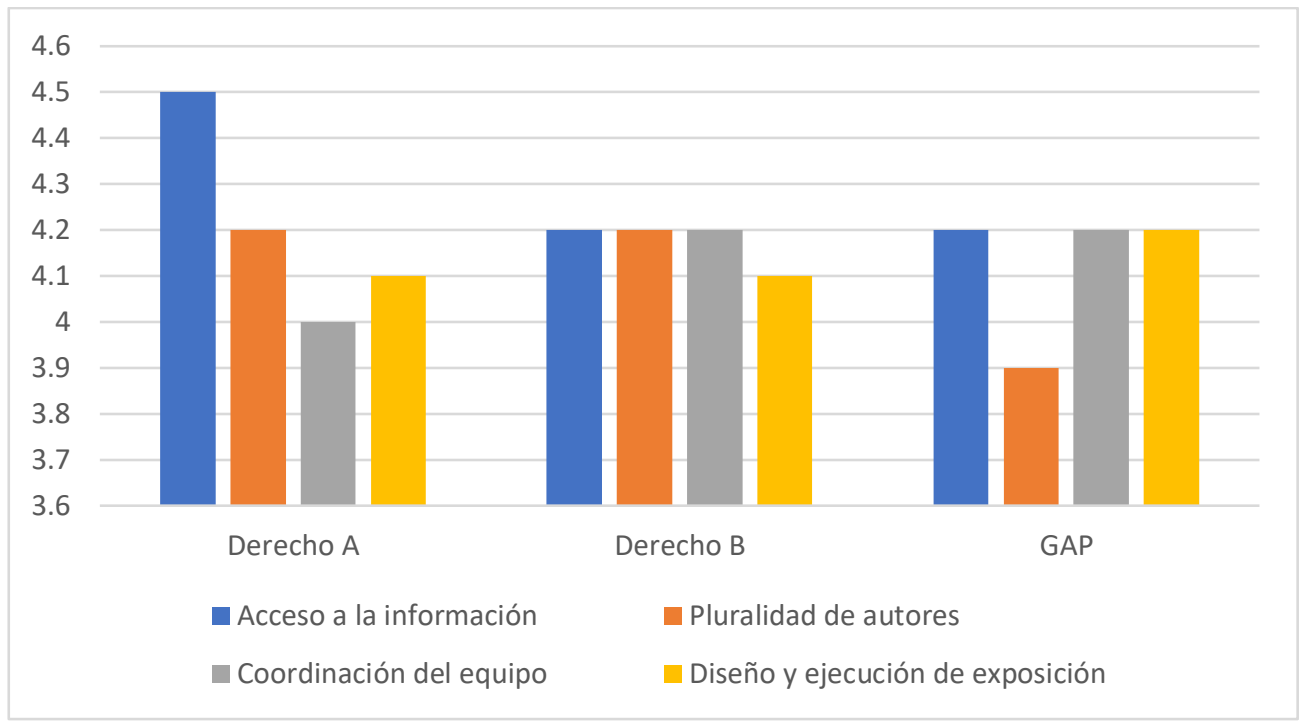

Gráfico 3. Valora los siguientes elementos de la exposición en cuanto a su grado de adaptación a un formato de clases semipresenciales y/o virtuales (1-5). Elaboración propia.

\subsection{Grado de desarrollo de conocimientos y efectos sobre el propio juicio.}

En el segundo apartado de la encuesta, hemos intentando saber si existía un conocimiento y una opinión previa en torno a la cuestión de debate y si se ha producido algún cambio tras la exposición. La cuarta pregunta muestra como el $65 \%$ o más de los alumnos consultados en cada clase sí tenía un conocimiento anterior sobre el tema que había trabajado (gráfico 4). En cambio, el porcentaje de encuestados que tenía un mayor desconocimiento sobre alguno de estos ítems se corresponde con los estudiantes del Grado en Gestión y Administración Pública, con más de un 35\% que no había tenido un acercamiento anterior.

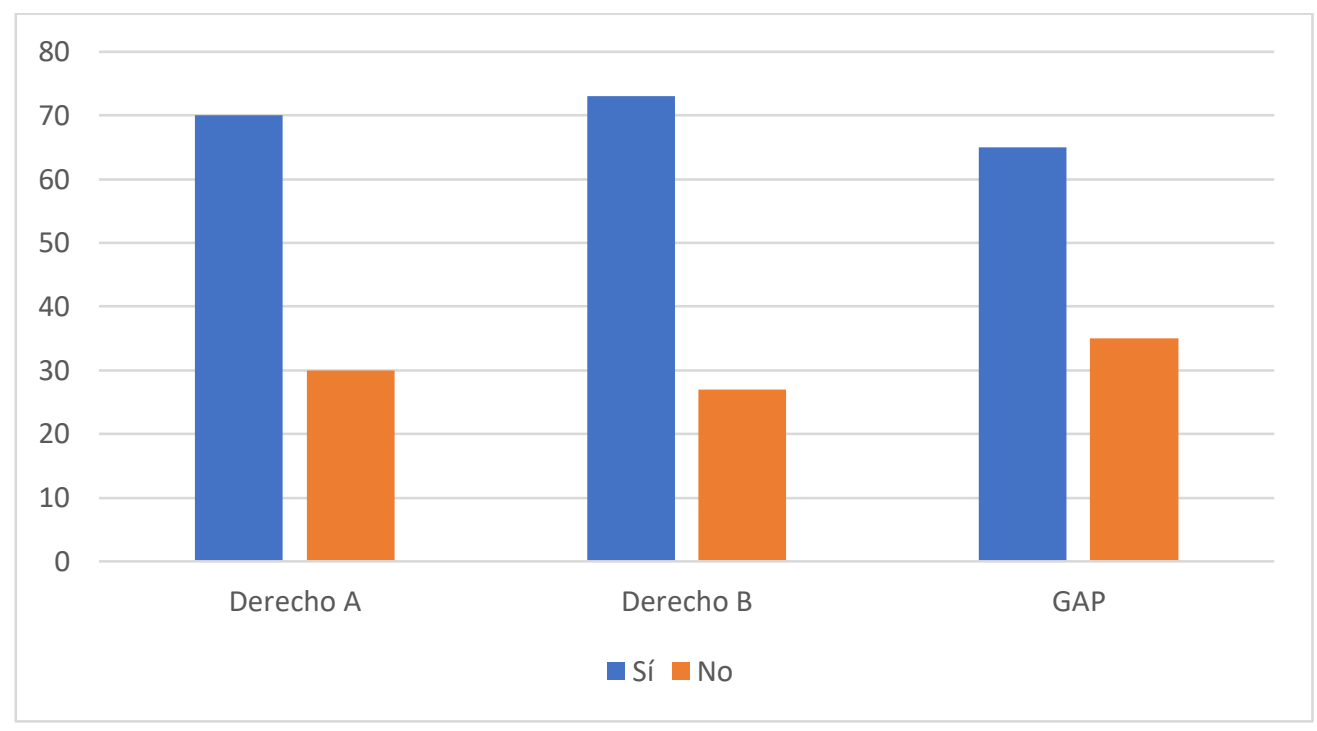

Gráfico 4. ¿Tenías conocimiento sobre la cuestión de debate que trabajaste en tu exposición previamente a la realización de este trabajo? Elaboración propia.

Cuando preguntamos si la realización de la práctica ha supuesto una mejora o un aumento del conocimiento en torno a la cuestión, más del 95\% de los encuestados lo afirma (gráfico 5). En este sentido, podemos afirmar que este tipo de trabajos permite 
complementar el aprendizaje transmitido en las clases teóricas. Sin embargo, hay que relativizar los datos especialmente en el Grado en Gestión y Administración Pública donde la cuota de alumnos que ha respondido a la encuesta es baja.

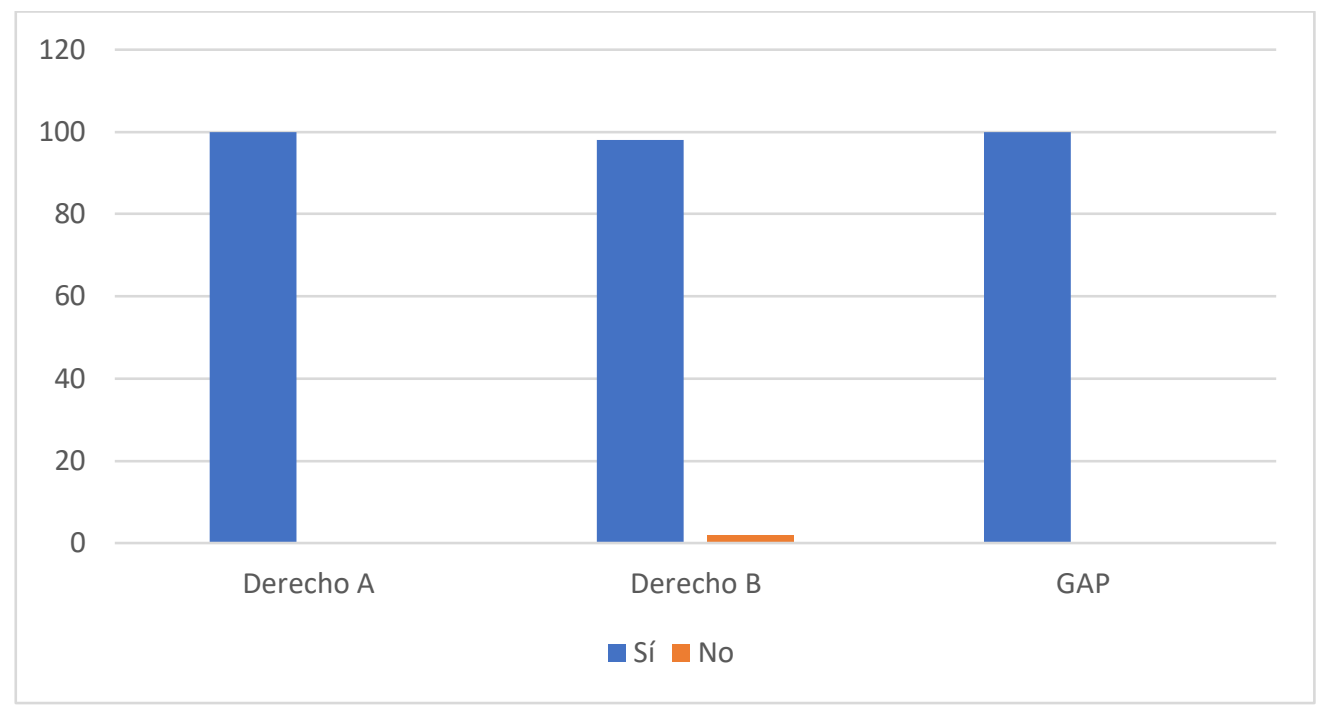

Gráfico 5. ¿Consideras que has adquirido algún conocimiento sobre la cuestión de debate después de la realización del trabajo? Elaboración propia.

La siguiente cuestión interroga a los alumnos si tenían una opinión o juicio personal sobre el tema que han tratado antes del trabajo (gráfico 6). Estos datos deben ser analizados en relación con la cuarta pregunta que consulta si existía un conocimiento anterior. En ese sentido, existe una coherencia entre el porcentaje de estudiantes que sabían algo sobre el tema y aquellos que tenían una opinión previa en sobre el mismo en las dos clases del Grado en Derecho. En cambio, debemos señalar una disonancia en el Grado de Gestión y Administración Pública. En este grupo, un 65\% de los alumnos encuestados desconocían el tema que abordaban en su exposición, pero paradójicamente un sector del $85 \%$ tenía una opinión previa sobre un asunto al que nunca se había acercado hasta este momento. Por tanto, entre esta clase un sector de los estudiantes consultados que tenían un prejuicio sobre el tema analizado en su trabajo sin tener un conocimiento sobre el mismo. Es interesante este dato, ya que esta práctica puede servir para evitar este tipo de incoherencias cognitivas y garantizar que el alumno tiene tanto un conocimiento como una opinión sobre un tema determinado. 


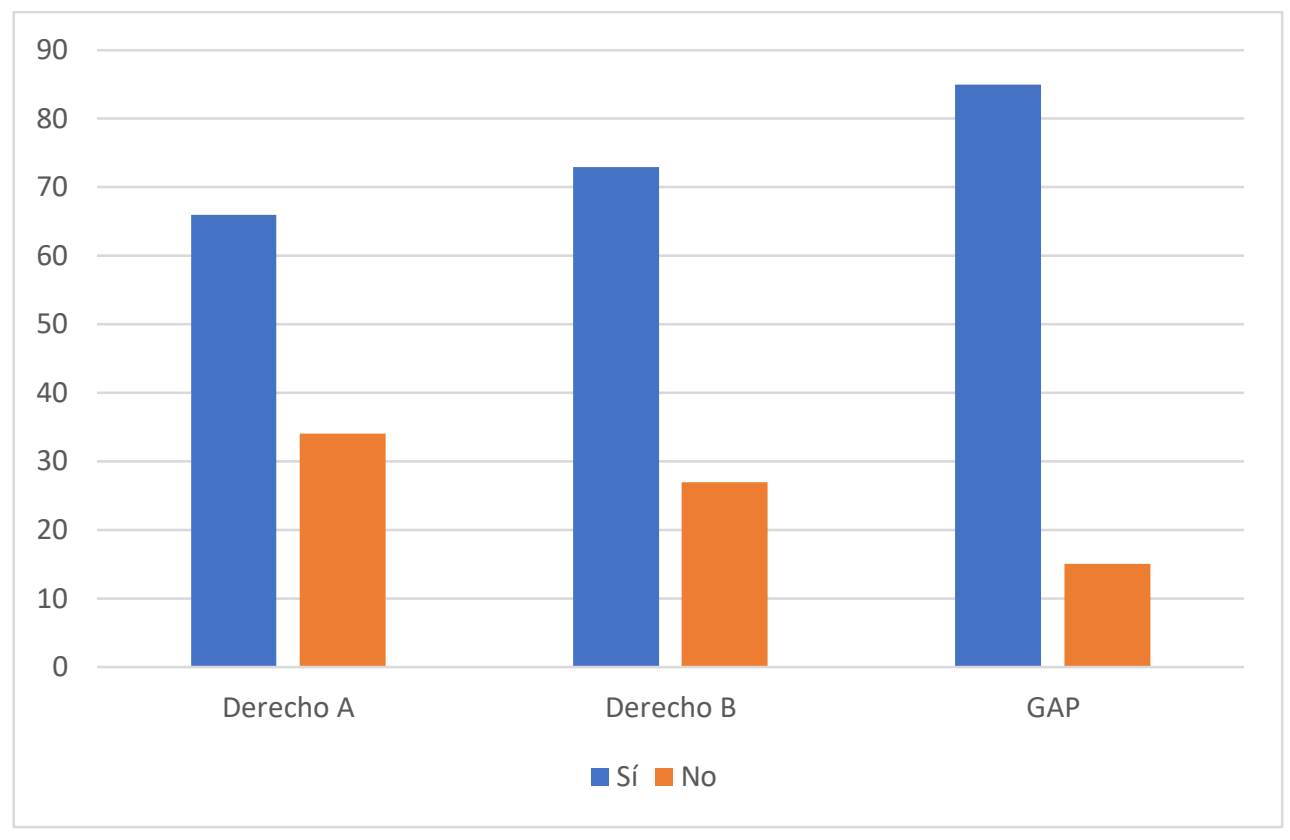

Gráfico 6. ¿Tenías alguna opinión o juicio propio sobre la cuestión de debate que trabajaste en tu exposición previamente a la realización de este trabajo? Elaboración propia.

Posteriormente, se observa que al menos la mitad de los estudiantes encuestados han cambiado su opinión sobre el tema en cada clase, aunque desconocemos si el factor que ha tenido más peso ha sido el acercamiento cognitivo al tema o la interacción con sus compañeros de equipo para alcanzar una postura en común en la exposición (gráfico 7). Por lo que en futuras encuestas, debemos incluir una pregunta para recabar más información sobre las causas del cambio de su juicio personal. Además, se puede destacar como existe una mayor capacidad de cambio de actitudes entre los alumnos consultados en el Grado en Derecho frente a los del Grado en GAP.

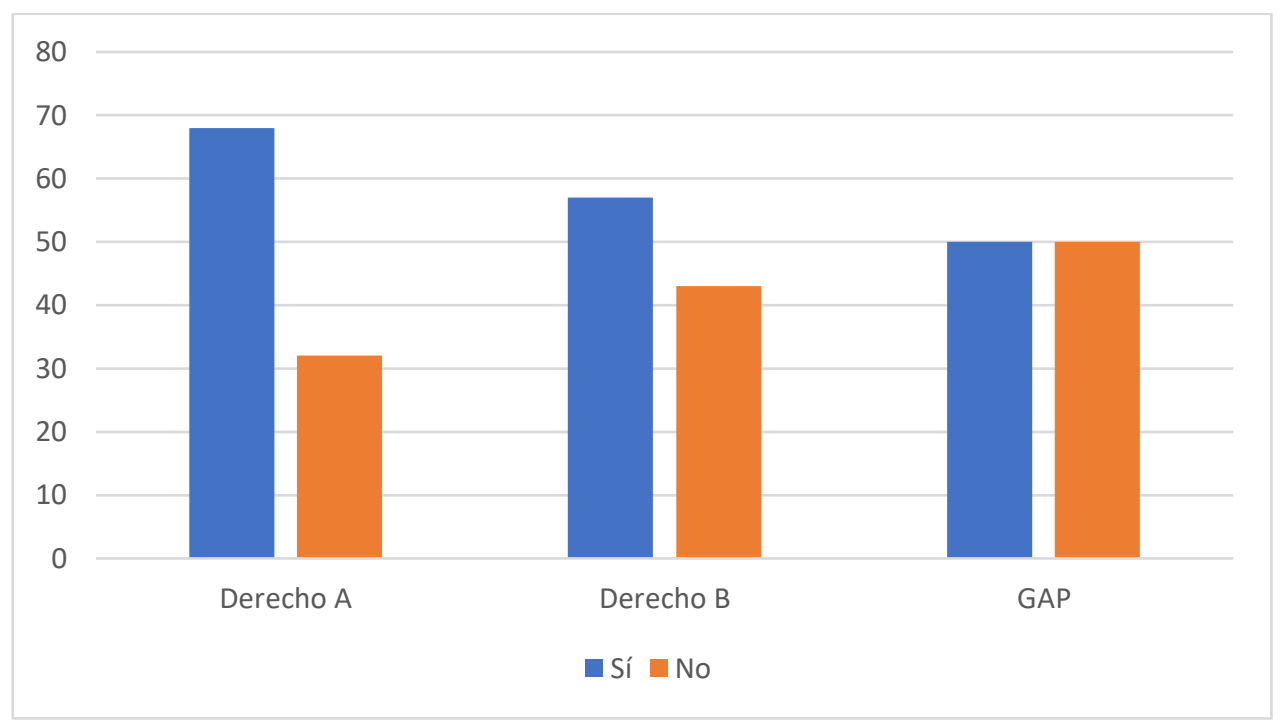

Gráfico 7. ¿Has adquirido (en caso de que no la tuvieses antes) o has cambiado tu opinión o juicio propio sobre la pregunta de debate que trabajaste tras la realización de este trabajo? Elaboración propia. 


\subsection{Desarrollo de las competencias personales tras la práctica.}

El grado de cumplimiento de las competencias personales se sitúa en general en un rango medio alto entre los alumnos consultados con valores entre 3,5 hasta 4,5 en una escala Likert (gráfico 8). Las competencias con una calificación más alta son interés por la política con una media de 4,06 y juicio crítico con una media de 4,03 en las puntuaciones obtenidas en cada clase. En tercer lugar, se encuentran tanto la capacidad de argumentación como la capacidad de consenso con una media de 3,9 en ambos casos. Por último, las habilidades que mantienen un índice más bajo de consecución son la tolerancia y la exposición en público con una valoración media de 3,6. Los índices más bajos dentro de las clases los encontramos en el 4,3 en interés por la política en el Grado en Gestión y Administración Pública y el 3,4 en tolerancia para la clase A del Grado en Derecho.

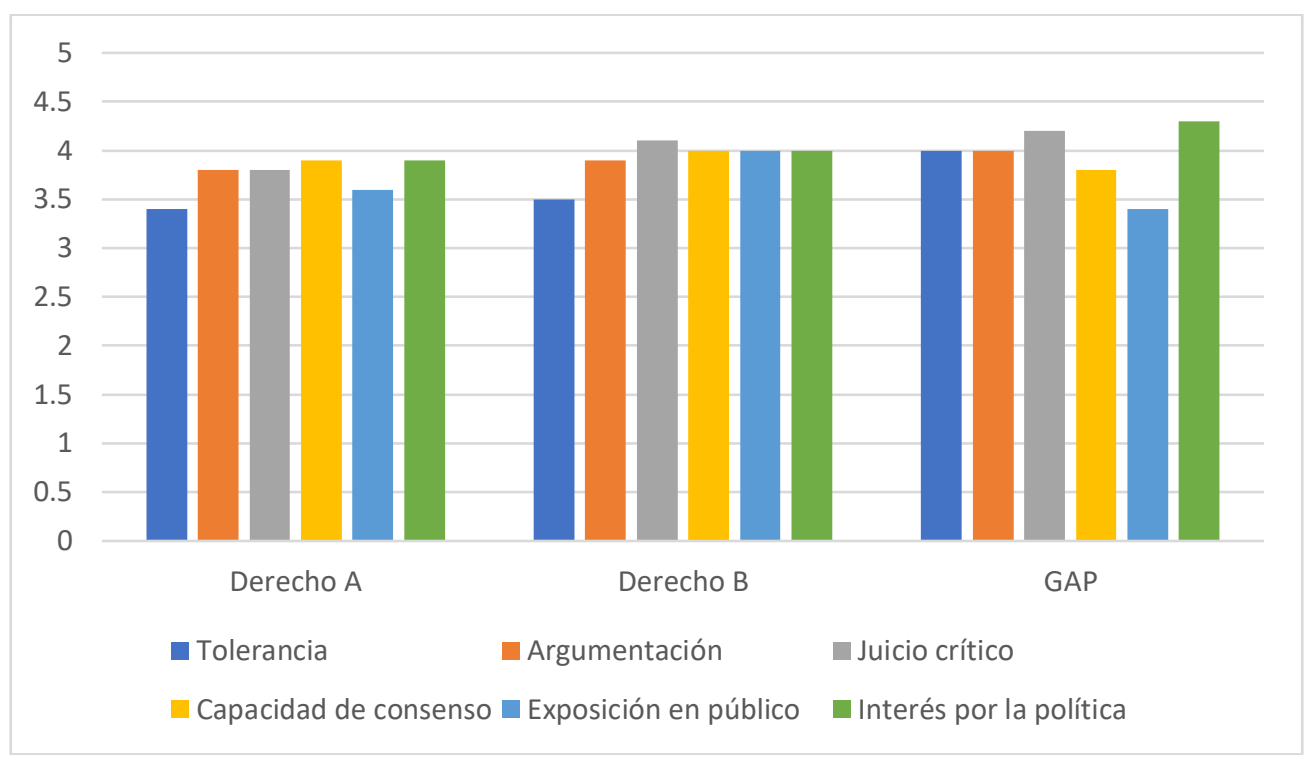

Gráfico 8. Valora si has experimentado algún cambio en alguna de tus siguientes competencias personales, después de la realización de la exposición (1-5). Elaboración propia.

\subsection{Valoraciones y recomendaciones cualitativas de los alumnos}

La amplia variedad de respuestas recibidas por parte de los estudiantes cuando les hemos preguntado qué han aprendido a través de esta práctica y que cambiarían para su mejora es difícilmente reproducible en el espacio de un artículo. Sin embargo, vamos a destacar cuáles son los elementos positivos y negativos que se repiten entre los encuestados de las tres clases para ambos ítems.

En la cuestión referida a qué han aprendido, las respuestas que más se destacan con un carácter positivo son aquellas referentes a la tolerancia y la pluralidad, la búsqueda de consenso y el trabajo en equipo. Este último que no habíamos tenido en cuenta de forma expresa, pero sí latente mediante la exigencia que los alumnos alcanzasen un acuerdo es un elemento fundamental de este trabajo. Por lo cual consideramos que es preferible que se realice de forma colectiva en lugar de individualmente. También es cierto que se percibe una mayor valoración de la mejora de los elementos cognitivos entre los alumnos del Grado en GAP. En cuanto a las valoraciones negativas más habituales en esta pregunta se debe destacar la falta de competencias de los alumnos para hablar en público y la escasa duración de la exposición, sobre todo entre los consultados en el Grado en Derecho. 
En la pregunta en torno a las futuras mejoras de esta formación práctica las más habituales son las referidas a la ampliación del tiempo de exposición, las problemáticas encontradas en el seno de los grupos para organizar las tareas, dificultades de adaptación tecnológica encontradas en la plataforma de Google Meet y la preferencia por la realización de esta práctica en un entorno de docencia presencial. Por lo que, entre los criterios que se deben tomar de cara a futuras ediciones deben centrarse en la ampliación de la duración de la exposición, la búsqueda de una plataforma más adecuada en caso que la puesta en escena se realice de forma virtual y la dedicación de algunas sesiones a la tutorización de los distintos grupos de trabajo.

\section{Conclusiones.}

Desde el equipo de profesores que hemos participado en el diseño y la ejecución de esta propuesta docente hemos intentado plantear una formación práctica en Ciencia Política que ejercite competencias básicas de la disciplina a la par que refuerce el conocimiento teórica de la materia. Estas competencias básicas se han extraído a partir de las definiciones de la política entre los principales manuales de la asignatura en España y se ha procurado establecer un vínculo entre estas competencias y los valores básicos de una democracia moderna. A partir de esta postura, las competencias de la tolerancia, la argumentación, el juicio crítico, la búsqueda del consenso, la expresión en público y el interés por la materia son a nuestro modo de ver las capacidades que deben ser ejercitadas por los estudiantes de esta disciplina.

Este diseño e implementación habría sido deseable que se hubiese ajustado a un entorno de docencia presencial. Sin embargo, esta preferencia no ha sido una opción para los docentes debido a la situación de incertidumbre que ha planteado y plantea el coronavirus. Por eso, se decidió realizar un diseño que tuviese en cuenta las posibles dificultades que se derivasen de esta situación, viendo esta situación más como una oportunidad que como una limitación. De ahí, que esta propuesta de formación práctica esté mejor adaptada para un entorno de semipresencialidad y virtualidad, al menos en su momento inicial.

El cumplimiento de los objetivos planteados inicialmente y el desarrollo de los trabajos se corresponden con las expectativas originarias, especialmente en el cumplimiento de las competencias por parte de los estudiantes y en la orientación ético-política que deseamos conceder a esta dinámica. Sin embargo, hay elementos que pueden ser mejorables o cambiados hacia el diseño original como la búsqueda de la duración adecuada de las exposiciones que por nuestra experiencia se puede situar en torno a los 15 minutos como se ha ejecutado en el Grado en GAP. Asimismo, otras dificultades están relacionadas con conocimientos y/o competencias ajenas a la asignatura como son las habilidades comunicativas y sociales especialmente en cuanto a su expresión en público y conocimientos relacionados con las distintas plataformas de conferencias y videoconferencias en Internet. Paradójicamente, una de las críticas que esperábamos recibir era referente a las cuestiones de debate seleccionadas en cada tema, pero las cuales no hemos recibido entre los encuestados. No obstante, es posible alterar tanto los temas como las cuestiones de debate en función de la programación que se haga de esta asignatura siempre que se siga el mismo procedimiento. Lo que sí recomendamos es que exista una relación entre las clases teóricas y la tematización de los trabajos en grupo.

Cabe destacar algunas de las mejoras que pueden ser introducidas: la redefinición del tamaño de los grupos, el establecimiento de criterios de selección la obligatoriedad o voluntariedad de la actividad práctica y la adecuada inserción de los estudiantes de Movilidad y aquellos con diversidad functional. También, una transformación vital reside en el paso de un modelo de caja negra a uno de caja blanca, es decir, que el profesor 
abandone su rol como guía y puede incluso participar activamente en las actividades de los equipos de trabajo.

Consideramos que las actuales transformaciones políticas, económicas y sociales se han visto completadas por el carácter poliédrico de las crisis producidas por el covid-19. Por ello, es fundamental que los estudiantes de las asignaturas introductorias a la Ciencia Política tengan las competencias adecuadas para su desempeño profesional en el seno de las democracias representativas y puedan responder adecuadamente ante situaciones críticas como la actual. Además, estas competencias deberían desarrollarse dentro del respeto a la identidad y las convicciones de los estudiantes como cabe esperar de la pluralidad característica de un sistema democrático.

En definitiva, los estudiantes necesitan saber cuáles son los debates presentes en la Ciencia Política y en la vida pública, pero también deberían tener las herramientas para poder responder y/o enfrentarse a esos dilemas. A fin de cuentas, y como ya han postulado los politólogos, la vida en democracia supone conciliar el conflicto y el acuerdo dentro de unos cauces racionales y civilizados.

6. Bibliografía.

- ÁGUILA, R. (1997), Manual de Ciencia Política. Madrid: Trotta.

- CAMinAL, M. (2011), Manual de Ciencia Política. Madrid: Tecnos.

- CARRIZO, A. (2016), El debate académico de competición como instrumento para el aprendizaje de cuestiones de Derecho, Ciencia Política y Criminología. Memoria final del proyecto ID 2016/032. Salamanca: Universidad de Salamanca [en línea] https://gredos.usal.es/bitstream/handle/10366/135352/MID_16_032.pdf?sequenc $\mathrm{e}=1$.

- CROSS, A. (2003), Convencer en clase: argumentación y discurso docente. Barcelona: Ariel.

- ESTEBAN, J. (2005), Universidades reflexivas: una perspectiva filosófica. Barcelona: Laertes.

- GARCÍA, T., ARIAS-GUNDÍN, O., RODRÍGUEZ, C., FIDALGO, R. y ROBLEDO, P. (2017), "Metodologías activas y desarrollo de competencias en estudiantes universitarios con diferentes estilos de pensamiento", Revista d'Innovació Docent Universitària, núm. 9, pp. 66-80, [en línea] https://revistes.ub.edu/index.php/RIDU/article/download/17124/20179.

- JEREZ MIR, M. Y LUQUE, J. (2016), "Treinta años de Ciencia Política en España: profesionalización, expansión y ajuste”, Revista Española de Ciencia Política, núm. 40, pp. 179-215, [en línea] https://recyt.fecyt.es/index.php/recp/article/view/41238.

- JIMÉNEZ, M. P. (2010), 10 Ideas clave. Competencias en argumentación y uso de pruebas. Barcelona: Graó.

- MARAFIOTI, R. (2003). Los patrones de la argumentación: la argumentación en los clásicos y en el siglo XX. Buenos Aires: Biblos.

- MERCER, N. (1997). La construcción guiada del conocimiento: el habla de profesores y alumnos. Barcelona: Paidós. 
- ORTEGA RUIZ, M., REAL-DATO, J. y JEREZ MIR, M. (2021). "Late but not least? Spanish political science's struggle for the internationalisation in the twenty-first century", European Political Science.

- PRENSKY, M. (2015), El mundo necesita un nuevo currículum. Habilidades para pensar, crear, relacionarse y actuar. Madrid: SM.

- RODRÍGUEZ PRIETO, R. (2012), "El debate como estrategia de innovación docente: experiencias en Filosofía del Derecho y Teoría de la Cultura", Revista UPO Innova, vol. 1, pp. 493-503 [en línea] https://www.upo.es/revistas/index.php/upoinnova/article/view/124.

- SODARO, M. (2006), Política y Ciencia Política: una introducción. Madrid: McGraw Hill.

- VALLÈS, J. M. (2020), ¿Para qué servimos los politólogos? Madrid: La Catarata.

- VALLÈS, J. M. (2006), Ciencia Política: una introducción. Barcelona: Ariel. 